\title{
Factores que generan ansiedad a los pacientes en diálisis: influencia de la antigüedad del tratamiento
}

\author{
Andrés Moreno Rodríguez, Rosa Sanz García, Lourdes Benítez Ruiz, Rubén Romero López
}

Hospital Universitario Puerta del Mar. Cadiz

\section{Objetivos:}

Conocer los factores estresantes de los pacientes con insuficiencia renal crónica durante las sesiones de hemodiálisis dependiendo del tiempo que llevan recibiéndolas.

\section{Material y método:}

Diseño: Estudio prospectivo y descriptivo diferenciando a los pacientes que llevaban menos de un año en hemodiálisis con los que llevan más de un año.

Ámbito: Unidad de hemodiálisis de un hospital universitario de referencia.

Periodo de estudio: Año 2012.

Sujetos: Pacientes con insuficiencia renal crónica en hemodiálisis.

Protocolo: Recogida durante la sesión de hemodiálisis.

Variables: Las constitutivas de la Escala de Ballard, sexo, edad, tiempo en hemodiálisis.

\section{Resultados:}

Se entrevistaron 30 pacientes. El $56,5 \%$ de los enfermos llevan más de un año en diálisis, de ellos el 64,7 \% eran hombres, edad media: 62 (34-87) años, tiempo medio en diálisis 33 (13 -108) meses. Los factores que más ansiedad producen en estos enfermos son: La diferencia de temperatura 35,5\%.Tener las manos inmovilizadas en algún momento $29,5 \%$. Oír hablar demasiado alto a médicos y enfer- meras $29,5 \%$. La presencia de olores extraños $35,5 \%$. Los enfermos que llevaban menos de un año en diálisis representaban el $43,5 \%$, de ellos el $38,5 \%$ eran hombres, edad media: 65 (41-80) años, tiempo medio en diálisis 8 ( 3 -12) meses. Los factores que más ansiedad producen en estos enfermos son: Tener dolor $76 \%$. Que le realicen pruebas y manipulaciones molestas y dolorosas $46,2 \%$. Dificultad/Imposibilidad para dormir $61,6 \%$. Oír muchos ruidos $38,5 \%$.

\section{Discusión:}

En nuestra unidad los factores que aumentan el nivel de ansiedad a los pacientes durante la sesión de hemodiálisis son diferentes dependiendo del tiempo que lleve en hemodiálisis. El factor más estresante en los pacientes que Ilevan en diálisis menos de un año es el dolor seguido de la dificultad para el descanso. En cambio cuando el paciente lleva más de un año con sesiones de hemodiálisis son los factores ambientales como los olores, ruidos y temperatura los que más estrés le producen.

\section{Referencias Bibliográficas}

1. BALLARD. Factores ambientales estresantes percibidos por los pacientes de una Unidad de Cuidados Intensivos Ayllón Garrido, N; Álvarez González, M; González García, M Publicado en Enferm Intensiva. 2007;18:159-67.

2. Vol.18 núm 04 Emotional disorders and psychological needs of patients in an Intensive Care Unit Med. Intensiva v.31 n.6 Madrid ago.-sep. 2007P Gómez-Carretero A, V Monsalve B, JF Soriano C, $\mathrm{J}$ de Andrés $\mathrm{D}$. 